\title{
In this issue
}

\author{
Richard Strange ${ }^{1}$
}

Published online: 21 September 2016

(C) Springer Science+Business Media Dordrecht and International Society for Plant Pathology 2016

The 10 papers comprising this issue of Food Security emphasise the dynamic nature of food security. Nothing stands still: everything changes over time, requiring constant monitoring and adjustment of policies in order to maintain just the (inadequate) level of food security we have, let alone improve it. Remarkably, four of the 10 papers feature different challenges to food security in one country, Tanzania: these are the spread of a devastating disease of bananas, the development of biofuel feedstock operations, rapid urbanisation and population growth, and the effect of price spikes in staple crops.

In the first paper, K H Anantha and Suhas Wani report on the monitoring of a watershed project in Southern India. This has been a considerable success, mitigating the effects of drought on household income and increasing the yields of maize intercropped with pigeonpea by up to $148 \%$, pigeonpea by $100 \%$, sorghum by $91 \%$ and cotton by $76 \%$.

Lina Jaber and co-authors point out that demand for livestock in the Arab region is increasing and assess its role in terms of food security by reference to data from Morocco and Saudi Arabia. On the supply side, local livestock production is largely based on rainfed mixed and pastoral livestock, making it vulnerable to climate change and water scarcity. Arbitrary national policies have had a particularly negative effect on smallholder producers and have contributed to the degradation of natural resources. Consequently, the authors propose a propoor policy framework for the development of a sustainable Arab livestock sector.

Richard Strange

r.strange@ucl.ac.uk

1 University College London, London, UK
James Sumberg and co-authors investigated the evolving protein economy in Ghana in the light of current debates about the nutritional transition and the livestock revolution. Fish and livestock probably provide between 20 and $40 \%$ of protein consumed by Ghanaians, with most of this being supplied through fish. However, the authors found that fish was becoming less important and poultry more important, but these changes were not taking place uniformly over the country but rather at different speeds and in different ways along an axis that is urban-south-non-poor at one end, and ruralnorth-poor at the other. An important factor is the increased import of protein rich foods supplied by producers in Brazil, Europe, the USA and Burkina Faso. As a result, near selfsufficiency in protein-rich foods in Ghana has declined to $50 \%$ in the last few years.

In a survey by Abid Hussain and co-authors of over 8000 households in four river sub-basins of the Hindu-Kush Himalayan region, the majority claimed that they had experienced increased incidences of floods, landslides, droughts, livestock diseases and crop pests. They attributed these to climate change. As a result, there have been low yields of almost all staple and cash crops and consequently low income. As coping mechanisms, households have made changes in their farming practices and some have migrated. In order to increase food security and resilience, the authors suggest a variety of policies, including changes in types of crops, investment in post-harvest facilities and diversification into nonfarming activities in order to generate income.

Mpoki Shimwela and co-authors found that a devastating wilt disease of bananas (BXW), caused by the recently introduced bacterium, Xanthomonas campestris pv. musacearum $(\mathrm{Xcm})$, continues to spread in Tanzania, despite an intensive campaign to remove symptomatic plants. The highest incidence of BXW occurred during rainy seasons as determined by SaTScan and extension officers, a result consonant with 
farmers' observations. Another factor that aggravates spread of the disease is the use of non-sterilized tools during the removal of symptomatic plants. The authors therefore recommend, among their disease management practices, cutting affected plants only during dry periods and using fire to sterilize farm tools.

There is a continuing debate as to whether the production of biofuel feedstock in developing countries compromises food security owing to competition for land that might otherwise be used for food crops. Stephen Thornhill and co-authors studied households in Mozambique and Tanzania situated close to different types of biofuel operations and comparable households further away. Those households with employees in medium to large-scale biofuel feedstock operations were significantly more food secure than those that did not have such employees. This result was attributed to higher and more regular income from salaried employment. However, an important conclusion of the authors is that biofuel investments "should only be facilitated by governments in food insecure countries where there is clear evidence of available land that is not in existing use or required for local food needs and where companies can provide evidence of economic and environmental sustainability".

Hugh Wenban-Smith and co-authors report that Tanzania has achieved broad self-sufficiency in basic foodstuffs to date but that rapid urbanisation will present challenges in the future. In particular, the disadvantaged poorer people of towns and cities are liable to face problems of food affordability, stability and safety. Success in avoiding deterioration of food security will depend on how responsive and resilient the urban food supply systems prove to be in the face of continuing urban growth, changing consumption patterns, weak ruralurban food supply linkages and production constraints in the smallholder farming sector.

Rising food prices are liable to have negative influences on nutritional outcomes. Xiaohua Yu and Satoru Shimokawa investigated the effects of price spikes in six African countries: the Democratic Republic of the Congo, Ethiopia, Malawi,
Nigeria, Tanzania and Uganda. They found that the negative effect was greatest when countries were dependent on a single staple cereal and suggest that stabilizing cereals prices would be important in reducing calorie deficiency but may not be sufficient to reduce protein deficiency.

Oren Koren and Benjamin Bagozzi contend that in many developing countries, widespread limitations to food access and availability may affect the location of armed conflict. This is because those areas that do have access to food are vulnerable to capture by armed groups. Thus, political violence is liable to occur in areas where food is readily available within or adjacent to areas where it is not.

Zero-tillage (ZT) is a successful technique for increasing the productivity of wheat but requires tractors and specialized seed drills for its implementation. Alwin Keil and co-authors show in their paper that only $8.3 \%$ of farmers in the Eastern Indo-Gangetic plains own tractors and consequently there is scope for developing custom hiring services for ZT equipment. They found that ZT service providers were generally larger-scale, tractor-owning farmers who have taken up service provision as a side business since 2010 or later. However, the authors conclude that small-scale tractor-owning farmers are the most sensible targets for purchase subsidies for ZT equipment as their comparatively low returns from agriculture reduce the opportunity costs of engaging in service provision.

Ulrike Grote highly recommends Eugenio Díaz-Bonilla's Macroeconomics, Agriculture and Food Security: A Guide to Policy Analysis in Developing Countries, finding the book a rich guide to the macroeconomics of agriculture and food security.

Malcom Blackie was impressed with Save and Grow in practice: Maize, rice, wheat; a guide to sustainable production edited by Reeves, Thomas and Ramsay. The book is a review of the five components of "Save and Grow"; conservation agriculture, healthy soils, improved varieties, efficient water management and integrated pest management. 